Article

\title{
Active Packaging-Poly(Vinyl Alcohol) Films Enriched with Tomato By-Products Extract
}

\author{
Katalin Szabo ${ }^{1}\left(\mathbb{D}\right.$, Bernadette-Emoke Teleky $^{1}\left(\mathbb{D}\right.$, Laura Mitrea ${ }^{1,2}{ }^{\circledR}$,

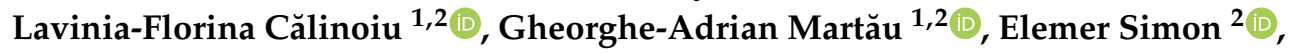 \\ Rodica-Anita Varvara ${ }^{2}$ and Dan Cristian Vodnar $1,2, *$ (D) \\ 1 Institute of Life Sciences, University of Agricultural Sciences and Veterinary Medicine, Calea Mănăştur 3-5, \\ 400372 Cluj-Napoca, Romania; katalin.szabo@usamvcluj.ro (K.S.); bernadette.teleky@usamvcluj.ro (B.-E.T.); \\ laura.mitrea@usamvcluj.ro (L.M.); lavinia.calinoiu@usamvcluj.ro (L.-F.C.); \\ adrian.martau@usamvcluj.ro (G.-A.M.) \\ 2 Faculty of Food Science and Technology, University of Agricultural Sciences and Veterinary Medicine, Calea \\ Mănăştur 3-5, 400372 Cluj-Napoca, Romania; simon.elemer@usamvcluj.ro (E.S.); \\ varvara.anita@yahoo.com (R.-A.V.) \\ * Correspondence: dan.vodnar@usamvcluj.ro; Tel.: +40-747-341-881
}

Received: 31 December 2019; Accepted: 3 February 2020; Published: 4 February 2020

check for updates

\begin{abstract}
Active films were prepared from poly(vinyl alcohol) (PVA) blended with itaconic acid (Ia), and with chitosan ( $\mathrm{Ch}$ ), enriched with tomato processing by-products extract (TBE) in order to develop new bioactive formulations for food packaging. The effects of two biopolymers (Ch, Ia) and of the incorporated TBE_-containing phenolic compounds and carotenoids—were studied regarding the physical and antimicrobial properties of films; in addition, their influence on the total phenolic content, viscosity, and flow behavior on the film-forming solutions was investigated. The results showed increased physical properties (diameter, thickness, density, weight) of the films containing the TBE versus their control. TBE and Ch conferred significant antimicrobial effects to PVA films toward all the tested microorganisms, whereas the best inhibition was registered against $S$. aureus and $P$. aeruginosa, with a minimum inhibitory concentration of $<0.078 \mathrm{mg} \mathrm{DW} / \mathrm{mL}$. The Ia-PVA films also exhibited some antibacterial activity against $P$. aeruginosa $(2.5 \mathrm{mg} \mathrm{DW} / \mathrm{mL})$. The total phenolic content of the film-forming solutions presented the highest values for the TBE and Ch-added PVA samples (0.208 $\mathrm{mg}$ gallic acid/100 $\mathrm{mL}$ film-forming solution). These results suggest that the PVA $+\mathrm{Ch}$ film containing TBE can be used for the development of intelligent and active food packaging materials.
\end{abstract}

Keywords: food packaging; poly(vinyl alcohol); by-product; carotenoids; itaconic acid; chitosan

\section{Introduction}

The mission of food packaging is to maintain the quality and safety of food products during storage and transportation by avoiding circumstances such as dangerous microorganisms, external physical forces, chemical compounds, sunlight, volatile permeable compounds, or oxygen; plastic packaging has these properties [1]. The worldwide use of plastics and plastic packaging $(\sim 26 \%$ of the total plastics) represents an indispensable element of the global economy, with an overall financial worth of 260 billion USD in 2013 and with an increase in the estimated industrial production from 78 million tons in 2013 to 350 million tons in 2017 [2,3]. Although plastics present valuable functional advantages, like low cost, versatile design, and light weight, it also has a number of negative features, such as freshwater pollution [4] and ocean pollution [5]. Over 90\% of plastics are made from fossil resources, which have a high impact on greenhouse gases (GHGs) and other serious adverse effects on the environment $[6,7]$. 
The European Commission disclosed the "European Strategy for Plastics in a Circular Economy" at the beginning of 2018, with a specific highlight on plastic production, reuse, and recycling. The main priority of the strategy is to abandon the use of fossil resources and to reduce GHG emissions through plastic manufacturing [8]. The goals of "Plastics 2030 Voluntary Commitment" are to achieve $60 \%$ recycling, reduction, and/or reuse of plastic until 2030 , and $100 \%$ by 2040 [9].

Bio-based materials help to reduce the use of non-renewable feedstock, which has decreased negative environmental effects (GHG emission) [10]. An efficient carbon-neutral alternative is the use of renewable biomass-wastes for biochemical production with efficient recyclability (mechanically, chemically, or through microbial degradation) [11]. The principal aspect is the replacement of fossil resources, but taking into consideration another significant aspect like biodegradability [12]. The characterization of biodegradability refers to thorough degradation to water and $\mathrm{CO}_{2}$ with the help of different types of microorganisms like fungi, bacteria, and algae [13,14].

Poly(vinyl alcohol) (PVA), presented in Figure 1A, is a polymer that has a backbone comprising only carbon atoms. PVA is water-soluble and biodegradable under both aerobic and anaerobic conditions. Indeed, the physical characteristics of PVA are deeply related to its method of preparation by complete or partial hydrolysis of polyvinyl acetate. Therefore, PVA can be classified according to the degree of hydrolysis: Fully hydrolyzed and partially hydrolyzed, and the partially hydrolyzed PVA is known to be used in foods [15]. For film development, PVA can be used due to its characteristics of having good film-forming capacity, complete biodegradability, crystal modulus, and wide-ranging crystallinity [16]. In addition, PVA is used in the food industry, as a binder, thickener, and/or stabilizer $[1,17]$.

A

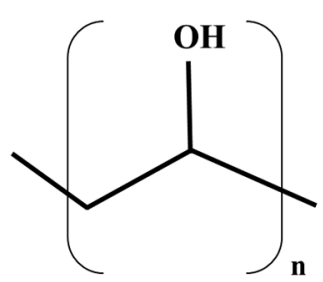

B<smiles>C=C(CC(=O)O)C(=O)O</smiles>

C

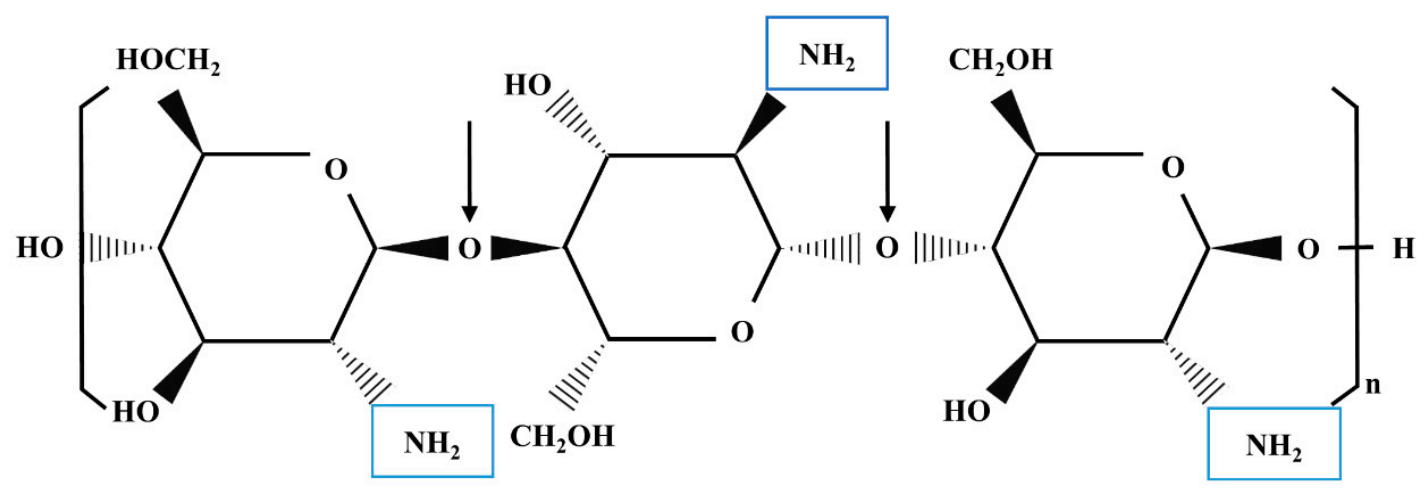

Figure 1. Chemical structures of poly(vinyl alcohol) (PVA) (A), itaconic acid (B), and chitosan (C).

Renewable biomaterials (like tomato processing by-products) are green options to reduce environmental pollution and waste formation $[18,19]$. In recent years, remarkable and creative ways of utilizing tomato by-products have delivered a continuous development for sustainable bioeconomy and biotechnology [20-22]. Tomatoes (Solanum lycopersicum), with an annual production of approximately 180 million tons (FAOSTAT, 2017), are one of the most popular vegetables worldwide. The processing of tomatoes for various foods such as sauces, ketchup, or juice generates significant quantities of by-products. About a quarter of total tomato production is subject to processing, which means that 
tomato peels, seeds, and small quantities of pulp are removed; these by-products can add around 5-30\% of the main product [23-25]. Phytochemicals found in industrial tomatoes and their by-products have been shown to include valuable compounds such as carotenoids, polyphenols, tocopherols, terpenes, and sterols. These bioactive compounds seem to resist industrial treatments [24,26-28].

As tomato peels have lycopene, $\beta$-carotene, lutein, and various phenolic compounds in their composition, they could be a source of natural bioactive molecules, applicable in the food industry, especially for bioactive packaging. In addition, the methanolic extracts of tomato peels showed antimicrobial activity against Staphylococcus aureus and Bacillus subtilis [18].

Itaconic acid (Ia), presented in Figure 1B, is one of the most favorable platform chemicals with relevant usage as a monomer or in monomer synthesis [29]. Due to versatile applications, the US Department of Energy included this bio-based unsaturated dicarboxylic acid in the first twelve building block chemicals obtainable from lignocellulose biomass [30]. Biotechnologically, this 5-C dicarboxylic acid is produced through fermentation of biomass with fungi like Aspergillus terreus and Ustilago maydis or with different metabolically engineered bacteria [31]. The production of Ia (approx. 41,000 tons/year), as a consequence of increased requests for bio-based materials, is in constant growth and is anticipated to surpass 216 million USD in 2020. Ia and its derivatives are efficiently used in the production of various innovative polymers and present an essential organic acid for manufacturing active packages in food applications [32]. Although Ia-based polymers present various applicabilities, the study of Ia incorporation in active packaging for the food industry is not well studied yet. However, the production of active packaging through the use of Ia presents an efficient solution for the incorporation and release of bioactive molecules with antimicrobial properties that can be used as food preservatives [33].

The use of existing molecules in nature (biopolymers or by-product extracts) to create active packaging is a future method for protecting food, stabilizing and protecting compounds against degradation or against different environmental factors. Biopolymers from different sources have been studied in recent years for food, biomedical, and pharmaceutical applications [34-36].

The global biopolymer market is expected to reach around 10 billion USD by 2021, increasing by almost 17\% over the forecast period 2017-2021 [37]. Western Europe has the largest market segment comprising $41.5 \%$ of the global market [35]. This development is due to the increasing use of biopolymers in various fields. Chitosan, presented in Figure 1C, is a non-toxic, biocompatible, and biodegradable biopolymer [38]. It can be used in the food industry, in applications for food packaging, for coating fresh and cut fruits or vegetables, and for the pharmaceutical industry as a microencapsulating agent or drug coating [39-44]. Numerous food components have been successfully protected, such as vitamins, antioxidants, enzymes, and minerals, due to chitosan's characteristics [45-50]. The observed antimicrobial activity of chitosan in numerous studies has led to the creation of biodegradable packaging or labels [51-54].

With increasing demand by consumers for safe and minimally processed food and a modern distribution system that requires a proper shelf life, active packaging is a viable option. The choice of active component must correspond to several factors, such as economy, safety, availability, and naturality. Herbal extracts have been widely used in the food industry as a substitute for synthetic additives. They are preferred for film development, mainly for their natural origin and phytochemical properties. The interaction between plant extracts and biopolymers could also influence the physico-chemical and techno-functional properties of the polymer [17].

The present paper aimed to investigate the antimicrobial potential of active films prepared from poly(vinyl alcohol) (PVA) with itaconic acid (Ia), and with chitosan (Ch), enriched with tomato processing by-products extract (TBE) in order to develop new formulas for active food packaging. The effects of two biopolymers (Ch, Ia) and of TBE, containing phenolic compounds and carotenoids, were studied on the physical and antimicrobial properties and the phenolic composition of films, as well as their influence on the viscosity and flow behavior on the film-forming solutions. 


\section{Materials and Methods}

\subsection{Materials}

Acetic acid, acetonitrile, itaconic acid, chitosan, ethanol, Folin Ciocalteu reagent, and other reagents implied in the experiments were of analytical grade, purchased from Sigma-Aldrich (Steinheim, Germany). PVA with high molecular weight, 98\%-99\% hydrolyzed, was purchased from ThermoFisher (Kandel, Germany). Carotenoid standards ( $\beta$-carotene), as well as chemicals used for antimicrobial assays, Mueller-Hinton agar, Mueller-Hinton broth, peptone special, tryptic soy broth, and resazurin, were purchased from BioMerieux (Marcy l'Etoile, France).

\subsection{Preparation and Characterization of Tomato Waste Extracts}

\subsubsection{Ultrasound-Assisted Extraction (UAE)}

By-products derived from tomato processing (tomato peels, seeds, and small amounts of pulp), were dehydrated in the dark, to avoid carotenoid loss, for $48 \mathrm{~h}$. Following dehydration, the by-products were finely ground and extracted with ethanol $98 \%(1: 5, \mathrm{w} / \mathrm{v})$ in an ultrasonic unit for 30 min. The extracts were separated from the solid phase in a centrifuge at 10,000 rpm, and the supernatant was filtered through a Millipore $0.45 \mu \mathrm{m}$. The obtained tomato by-product extract, further named TBE, was subjected to high-performance liquid chromatography (HPLC) coupled to mass spectrometry (MS) in order to determine the total and individual carotenoids and phenolic contents.

\subsubsection{Quantitative and Qualitative Analysis of Carotenoids (Lycopene, B-Carotene, and Lutein) by} HPLC/DAD

The TBE was injected into an Agilent 1200 HPLC system with a Diode Array Detector (Agilent Technologies, Santa Clara, CA, USA), and individual carotenoids were determined using a reversed-phase EC 250/4.6 Nucleodur 300-5 C-18 ec. Column $(250 \mathrm{~mm} \times 4.6 \mathrm{~mm})$ of $5 \mu \mathrm{m}$ (Macherey-Nagel, Düren, Germany). Mobile phase A consisted of a mixture of acetonitrile:water $(9: 1, \mathrm{v} / \mathrm{v})$ with $0.25 \%$ triethylamine, and mobile phase B was formed by ethyl acetate with $0.25 \%$ triethylamine. The gradient started with $90 \%$ mobile phase A at 0 min decreased to $50 \%$ A at 10 min and finalized with $10 \%$ mobile phase $\mathrm{A}$ at $20 \mathrm{~min}$. The flow rate was $1 \mathrm{~mL} / \mathrm{min}$, and the chromatograms were monitored at $450 \mathrm{~nm}$, common to carotenoids. The peaks were identified using carotenoid standards (lycopene, $\beta$-carotene, and lutein), and quantified on the basis of the calibration curve of a $\beta$-carotene standard.

\subsubsection{Qualitative and Quantitative Analysis of Phenolic Compounds by HPLC-DAD-ESI-MS}

Total and individual phenolic compounds of the TBE were determined on an HPLC-DAD-ESI-MS system consisting of an Agilent 1200 HPLC with a DAD detector, coupled to an MS-detector single-quadrupole Agilent 6110. The separation of phenolic compounds was performed at $25^{\circ} \mathrm{C}$ on an Eclipse column, XDB C18 (4.6 mm×150 mm, $5 \mathrm{~mm})$, with a binary gradient. Mobile phase A consisted of a mixture of $0.1 \%$ acetic acid:acetonitrile (99:1) in distilled water (v/v) and mobile phase B was formed by $0.1 \%$ acetic acid in acetonitrile (v/v), following the elution program used by Dulf et al. (2015) [55], at a flow rate of $0.5 \mathrm{~mL} / \mathrm{min}$. For MS fragmentation, the ESI (+) module was used with a capillary voltage of $3000 \mathrm{~V}$, a nitrogen flow of $8 \mathrm{~L} / \mathrm{min}$, and a scanning range situated between 100 and $1000 \mathrm{~m} / \mathrm{z}$ at $350^{\circ} \mathrm{C}$.

The phenolic compounds were monitored by DAD, and the absorption spectra (200-600 nm) were collected continuously during each run. Data analysis was performed using Agilent ChemStation Software (Rev B.04.02 SP1, Palo Alto, CA, USA). 


\subsection{Film Preparation}

First, three different PVA concentrations were tested for polymerization $(1,2$, and $3 \% \mathrm{wt}$.), and the optimum ratio for further experiments was selected to be PVA $3 \% \mathrm{wt}$. The PVA solution (3\% wt./v) was prepared in hot distilled water $\left(90^{\circ} \mathrm{C}\right)$ under continuous stirring for $2 \mathrm{~h}$. Further, the polymer films were prepared by the solvent casting technique.

PVA + Chitosan (PVA $+\mathrm{Ch})$ solution $(1 \% \mathrm{v} / \mathrm{wt}$.) was prepared by dissolving chitosan in acidified PVA solution at $80^{\circ} \mathrm{C}$ with continuous stirring (500 rpm) for two hours.

PVA + Itaconic acid (PVA + Ia) solution (1\% v/wt.) was prepared by adding itaconic acid to the PVA solution at $65^{\circ} \mathrm{C}$ with continuous stirring for $30 \mathrm{~min}$.

To the prepared PVA + Ch and PVA + Ia film-forming solutions, we added $9 \% \mathrm{v} / \mathrm{v}$ TBE under continuous stirring (500 rpm) at room temperature, and the resulting samples were subjected to antimicrobial capacity tests, rheological measurements, and total phenolic content determination.

Further, the TBE-added film-forming solutions together with control PVA solutions $(15 \mathrm{~mL})$ were cast in plastic Petri dishes $(8.5 \mathrm{~cm})$ and evaporated at room temperature $\left(21^{\circ} \mathrm{C}\right)$ for $48 \mathrm{~h}$. The obtained films were peeled off and stored for further investigations.

\subsection{Shear Viscosity Measurement of Film Solutions}

To examine the influence of tomato extract, $\mathrm{Ch}$, and Ia on PVA viscosity, the viscosity flow behavior of the PVA, PVA + TBE, PVA + Ia + TBE, and PVA + Ch + TBE solutions was measured through an Anton Paar MCR 72 rheometer (Anton Paar, Graz, Austria), equipped with a concentric cylinder system and a double-gap 42 measuring system (temperature range $5^{\circ} \mathrm{C}$ to $150{ }^{\circ} \mathrm{C}$ ). For each sample solution, approx. $15 \mathrm{~mL}$ was poured in the double-gap system of the rheometer. Each measurement was operated at $21^{\circ} \mathrm{C}, 30^{\circ} \mathrm{C}$, and $37^{\circ} \mathrm{C}$ with a shear rate of 5-300 (logarithmic ramp) and determination value in $0-100 \mathrm{~s}^{-1}$ (logarithmic ramp).

\subsection{Total Phenolics}

Determination of the total phenolic content was made by the Folin-Ciocalteu assay, which estimates the total content of all phenolic compounds present in the analyzed samples and measures the total reducing capacity of a sample. In order to test their reducing power, aliquots of $25 \mu \mathrm{L}$ PVA $+\mathrm{TBE}, \mathrm{PVA}+\mathrm{Ia}+\mathrm{TBE}$, and PVA + Ch + TBE samples were mixed with $1.8 \mathrm{~mL}$ distilled water in a 24well microplate. An aliquot of $120 \mu \mathrm{L}$ of Folin-Ciocalteu reagent was added to the wells and mixed, followed by the addition of $340 \mu \mathrm{L} \mathrm{Na}_{2} \mathrm{CO}_{3}(7.5 \% \mathrm{wt} . / \mathrm{v})$ solution, to create basic conditions for the redox reaction between phenolic compounds and Folin-Ciocalteu reagent. After incubation in the dark for $90 \mathrm{~min}$ at room temperature, the absorbance was read at $750 \mathrm{~nm}$ using a microplate reader (BioTek Instruments, Winooski, VT, USA). The analysis was repeated three times and the results were expressed as gallic acid equivalent/100 $\mathrm{mL}$ sample.

\subsection{Antimicrobial Activity of the Film-Forming Solutions}

For this bioassay, five bacterial strains were used: Staphylococcus aureus (ATCC 49444), Pseudomonas aeruginosa (ATCC 27853), Salmonella enterica serovar Typhimurium (ATCC 14028) and serovar Enteritidis (ATCC 31194), and Escherichia coli (ATCC 25922). The microorganisms were obtained from the Food Biotechnology Laboratory of the University of Agricultural Sciences and Veterinary Medicine Cluj-Napoca, Romania. The strains were cultured on Mueller-Hinton agar, stored at $4{ }^{\circ} \mathrm{C}$, and sub-cultured once a month.

To evaluate the antimicrobial potential of the film-forming solutions, the modified microdilution technique was used, described previously by Vodnar et al. (2017) [56]. In a 96-well plate, fresh overnight cell suspensions of the tested microorganisms were adjusted with sterile saline solution to a concentration of approximately $2 \times 10^{5} \mathrm{CFU} / \mathrm{mL}$ in a final volume of $100 \mu \mathrm{L}$ per well. The inoculum was stored at $4{ }^{\circ} \mathrm{C}$ until further use. Further, serial dilutions of the film-forming solutions were attained 
in the wells containing $100 \mu \mathrm{L}$ of nutrient broth. Afterward, $10 \mu \mathrm{L}$ of inoculum was added to all the wells. The microplates were incubated for $24-48 \mathrm{~h}$ at $37^{\circ} \mathrm{C}$.

The minimum inhibitory concentration (MIC) was determined as the lowest concentration of the film-forming solutions ( $\mathrm{mg} \mathrm{DW} / \mathrm{mL}$ ), inhibiting the visual growth of the tested microorganisms on the microplate. The MIC of the samples was determined after the addition of $20 \mu \mathrm{L}(0.2 \mathrm{mg} / \mathrm{mL})$ of resazurin solution to each well, as a color reactive (intense blue), and the plates were incubated for $2 \mathrm{~h}$ at $37^{\circ} \mathrm{C}$. A color change from blue to pink indicated the reduction of resazurin and, therefore, bacterial growth. The final concentrations of the tested film-forming solutions were approximately $27.3 \mathrm{mg}$ DW/mL for PVA, $9.1 \mathrm{mg}$ DW/mL for Ch/Ia, and $0.5 \mathrm{mg}$ DW/mL for TBE.

In order to interpret the results, we applied the guideline described by O'Donnell et al. (2010) [57], where the antimicrobial activity of the tested compounds is defined as follows: No bioactivity (MIC > $1000 \mu \mathrm{g} / \mathrm{mL}$ ), mild (MIC = 501-1000 $\mu \mathrm{g} / \mathrm{mL})$, moderate $(\mathrm{MIC}=126-500 \mu \mathrm{g} / \mathrm{mL}), \operatorname{good}(\mathrm{MIC}=26-125$ $\mu \mathrm{g} / \mathrm{mL}$ ), strong (MIC $=10-25 \mu \mathrm{g} / \mathrm{mL}$ ), and very strong bioactivity (MIC $<10 \mu \mathrm{g} / \mathrm{mL}$ ).

\subsection{Solid Film Characterization}

\subsubsection{Solid Film Measurements}

A ruler was used to measure the diameter of the obtained films, while the thickness was measured with a digital caliper. The weight of the film samples was measured with an analytical balance with 0.1 mg precision. The density of the films was established by using the following equation:

$$
\text { Density }\left(\mathrm{g} / \mathrm{cm}^{3}\right)=\mathrm{m} / \mathrm{s} \cdot \mathrm{t}
$$

where $\mathrm{m}$ is the mass of sample in grams; $\mathrm{s}$ is the surface of the sample in $\mathrm{cm}^{2}$; and $\mathrm{t}$ is the thickness of sample in $\mathrm{cm}$.

All measurements were performed at room temperature $\left(21^{\circ} \mathrm{C}\right)$.

\subsubsection{Fourier-Transform Infrared analysis}

The solid samples were analyzed using Fourier-transform infrared (FTIR, Shimadzu IR Prestige-21, Kyoto, Japan) equipped with an attenuated total reflectance (ATR) module with a single reflection from PIKE provided with the press. Films were applied directly to the horizontal accessory after which infrared absorption spectra were recorded in the wavelength range of $600-4000 \mathrm{~cm}^{-1}$, at a resolution of $4 \mathrm{~cm}^{-1}$, and with 64 scans for one spectrum. The spectral data obtained were processed using the IR Solution Software program Overview (Shimadzu) and OriginR 7SR1 Software (OriginLab Corporation, Northampton, UK).

\subsection{Statistical Analysis}

The measurements regarding physical properties and total phenolic contents were made in triplicate and the values are expressed as mean values $\pm \mathrm{SD}, n=3$. Only the variation in total phenolic content of the studied film-forming solutions was analyzed by one-way ANOVA, and the differences were examined by Tuckey's multiple comparison test $(p<0.05)$. Different letters on this particular chart indicate significant differences $(p<0.05)$ between the tested films (GraphPad Prism Version 8.0.1, Graph Pad Software, Inc., San Diego, CA, USA).

\section{Results and Discussion}

\subsection{Characterization of Tomato By-Products Extracts}

First, 11 bioactive compounds were identified in TBE belonging to the carotenoids and phenolic groups. From the carotenoids class, three main compounds were found: Lutein, lycopene, and $\beta$-carotene, while from the phenolics class, eight compounds were registered: Caffeic acid-glucoside 
isomer (CG), 5-caffeoylquinic acid (5-CQA), quercetin-diglucoside (QdiG), quercetin-glucuronide (QGl), quercetin-3-rutinoside (Q3R), di-caffeoylquinic acid (di-CQA), tri-caffeoylquinic acid (tri-CQA), and naringenin chalcone (NGC). The individual carotenoids and phenolic compounds identified in TBE's composition are illustrated in Figure 2 via HPLC chromatograms.

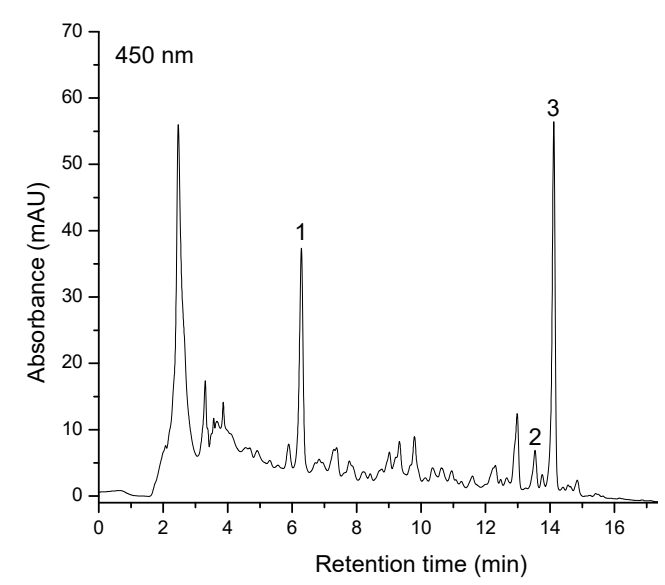

(A)

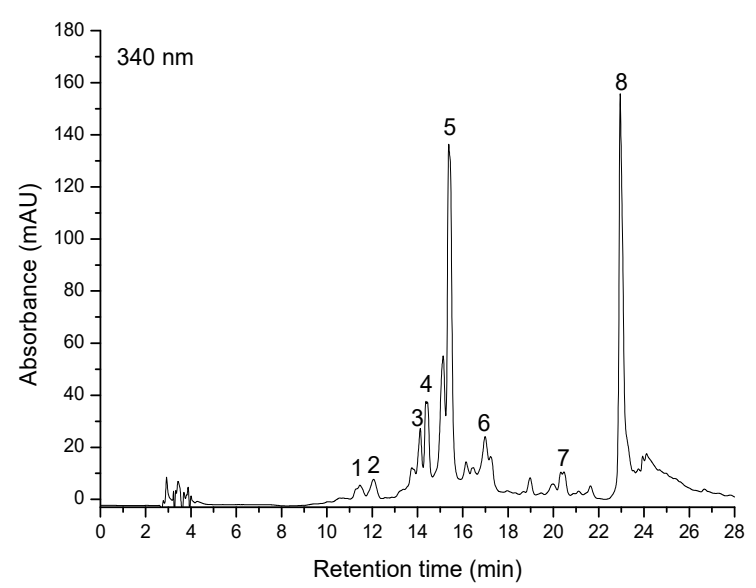

(B)

Figure 2. HPLC chromatograms of ethanolic tomato by-products extract for carotenoids (A) and for phenolic compounds (B).

Data regarding retention time, the wavelength along the absorption spectrum, or the mass to charge ratio $(\mathrm{m} / \mathrm{z})$ of the identified components are presented in Table 1.

Table 1. Identification of carotenoids and phenolic compounds in tomato processing by-products extract (TBE).

\begin{tabular}{cccccc}
\hline $\begin{array}{c}\text { Class of } \\
\text { Compounds }\end{array}$ & Peak No. & $\boldsymbol{R}_{\mathbf{t}}(\mathbf{m i n})$ & $\boldsymbol{\lambda}_{\max }(\mathbf{n m})$ & $\begin{array}{c}{[\mathbf{M}+\mathbf{H}]^{+}} \\
(\mathbf{m} / \mathbf{z})\end{array}$ & Compound \\
\hline \multirow{3}{*}{ Carotenoids } & 1 & 6.41 & 448,474 & & Lutein \\
& 2 & 13.42 & 446,473 & & Lycopene \\
& 3 & 14.51 & 455,480 & & 3-Carotene \\
\hline & 1 & 11.12 & 292,245 & 343 & Caffeic acid-glucoside isomer \\
& 2 & 11.93 & 326,248 & 355 & 5-Caffeoylquinic acid \\
Phenolics & 3 & 14.09 & 355,259 & 627 & Quercetin-diglucoside \\
& 4 & 14.87 & 355,259 & 478 & Quercetin-glucuronide \\
& 5 & 15.34 & 354,256 & 611 & Quercetin-3-rutinoside \\
& 6 & 16.98 & 328,250 & 517 & Di-Caffeoylquinic acid \\
& 7 & 20.33 & 328,250 & 679 & Tri-Caffeoylquinic acid \\
& 8 & 23.10 & 366,250 & 273 & Naringenin chalcone \\
\hline
\end{tabular}

The content of each carotenoid compound identified in TBE is presented in Table 2, where $\beta$-carotene had the highest content, followed by lutein. Considering that the aim of the study is to find new formulas for food packaging and/or biomedical applications, a food-grade solvent was used to extract the bioactive components from the tomato processing by-products, in one-step, which explains the lower concentration of carotenoids compared to earlier findings. Previous studies reported a lycopene content in the range from 14.9 to $28.3 \mathrm{mg} / 100 \mathrm{~g}$ DW; however, the used protocol was tailored for carotenoid extraction by organic solvents [58]. 
Table 2. Individual carotenoids content of TBE expressed in mg/100 DW ( $\beta$-carotene equivalent).

\begin{tabular}{ccc}
\hline Peak & Carotenoids & mg/100 DW \\
\hline 1 & Lutein & $1.549 \pm 0.04$ \\
2 & Lycopene & $0.127 \pm 0.01$ \\
3 & $\beta$-Carotene & $1.597 \pm 0.01$ \\
& Sum of identified carotenoids & $3.273 \pm 0.05$ \\
\hline
\end{tabular}

The carotenoids content, $3.273 \mathrm{mg} / 100 \mathrm{~g} \mathrm{DW}$, can increase the biological activity potential of TBE-based films considering their previously reported antioxidant and antimicrobial properties. In the study of Strati, Gogou, and Oreopoulou, the total carotenoids reported in tomato by-products extracts were in the range from 0.36 to $16.52 \mathrm{mg} / 100 \mathrm{~g}$ DW, considering the existing differences in the extraction method and tomato varieties [59].

The individual phenolic contents of ethanolic TBE are reported in Table 3. Naringenin chalcone, belonging to the flavonoid class, was the major phenolic compound identified, followed by quercetin-glucuronide (flavonol sub-class).

Table 3. Individual phenolic compounds content of TBE, expressed in mg/100 g DW (equivalents of chlorogenic acid and rutin).

\begin{tabular}{ccc}
\hline Peak & Phenolic Compounds & $\mathbf{m g} / \mathbf{1 0 0}$ DW \\
\hline 1 & Caffeic acid-glucoside isomer & $2.284 \pm 0.02$ \\
2 & 5-Caffeoylquinic acid & $2.623 \pm 0.02$ \\
3 & Quercetin-diglucoside & $7.150 \pm 0.05$ \\
4 & Quercetin-glucuronide & $24.427 \pm 0.04$ \\
5 & Quercetin-3-rutinoside & $6.061 \pm 0.03$ \\
6 & Di-Caffeoylquinic acid & $2.092 \pm 0.02$ \\
7 & Tri-Caffeoylquinic acid & $1.782 \pm 0.01$ \\
8 & Naringenin chalcone & $34.178 \pm 0.02$ \\
& Sum of identified phenolics & $80.596 \pm 0.20$ \\
\hline
\end{tabular}

\subsection{Shear Viscosity Measurement of Film-Forming Solutions}

The semi-crystalline polymer PVA consists of a hydroxyl group $(-\mathrm{OH})$ that generates intra- and intermolecular hydrogen bonding that has a strong influence on the mechanical and rheological characteristics of the polymer solutions [60]. Figure 3A-C present the relationship between viscosity and the shear rate of the PVA-based biopolymers at various temperatures.

The films PVA $+\mathrm{Ch}$ and PVA $+\mathrm{Ch}+\mathrm{TBE}$ for the investigated shear rate range presented pseudo-plastic (shear-thinning) behavior, and as can be seen in the figures (Figure $3 \mathrm{~A}-\mathrm{C}$ ), for all three temperatures, the viscosity decreased slowly with intensifying shear rate, which is a typical feature of polymer solutions. These pseudo-plastic materials at increasing shear rate have reduced shear viscosity, due to the alignment of the large molecular chains in the course of higher shear rate, which generates lower resistance [61,62]. However, with the increase in temperature, the viscosity presented higher values, and at higher shear rates, the viscosity also decreased exponentially.

The other films (PVA, PVA + TBE, PVA + Ia, PVA + Ia + TBE) presented a dilatant (shear-thickening) behavior. These dilatant materials with increasing shear rate have increased viscosity, but at shear rates higher than $30 \mathrm{~s}^{-1}$, the viscosity remained generally constant. The addition of Ia to the biofilms at $37^{\circ} \mathrm{C}$ increased the viscosity, and at a temperature of $21^{\circ} \mathrm{C}$, they presented a lower viscosity. The simple biofilms, which contained only PVA and PVA + TBE (small molecular-weight compounds) presented inverse viscosities. The addition of TBE did not influence the viscosity of the biofilms. 


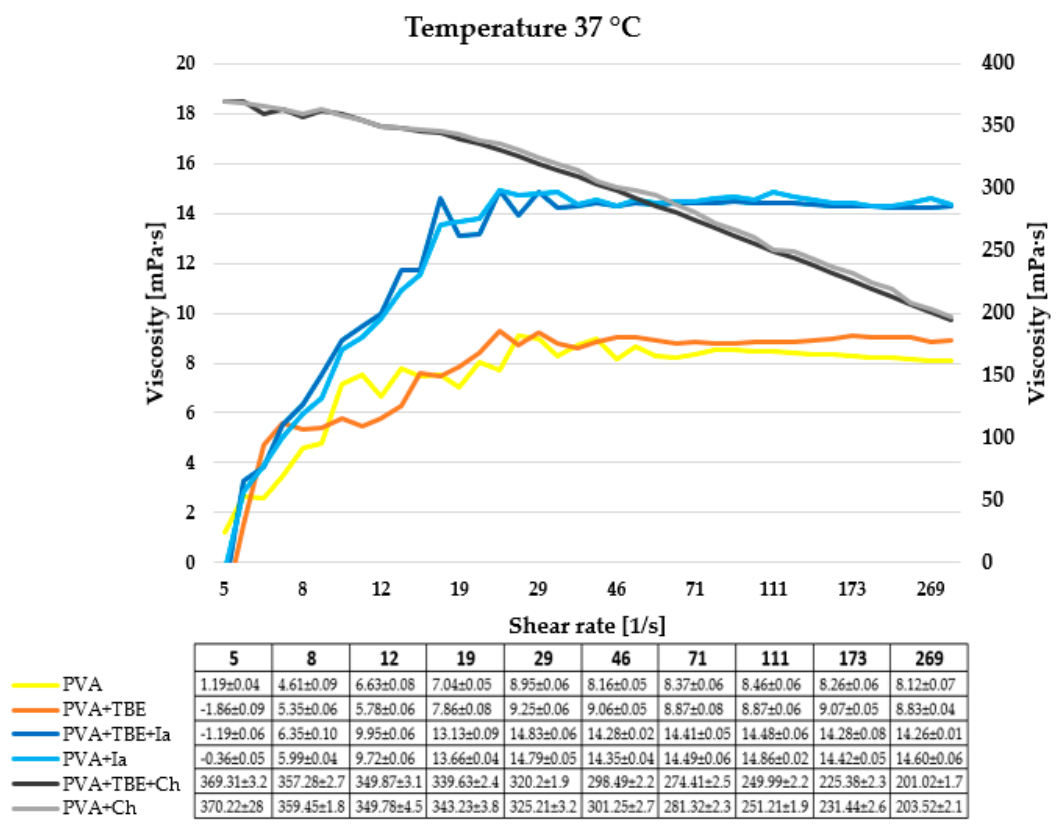

(A)

Temperature $30^{\circ} \mathrm{C}$

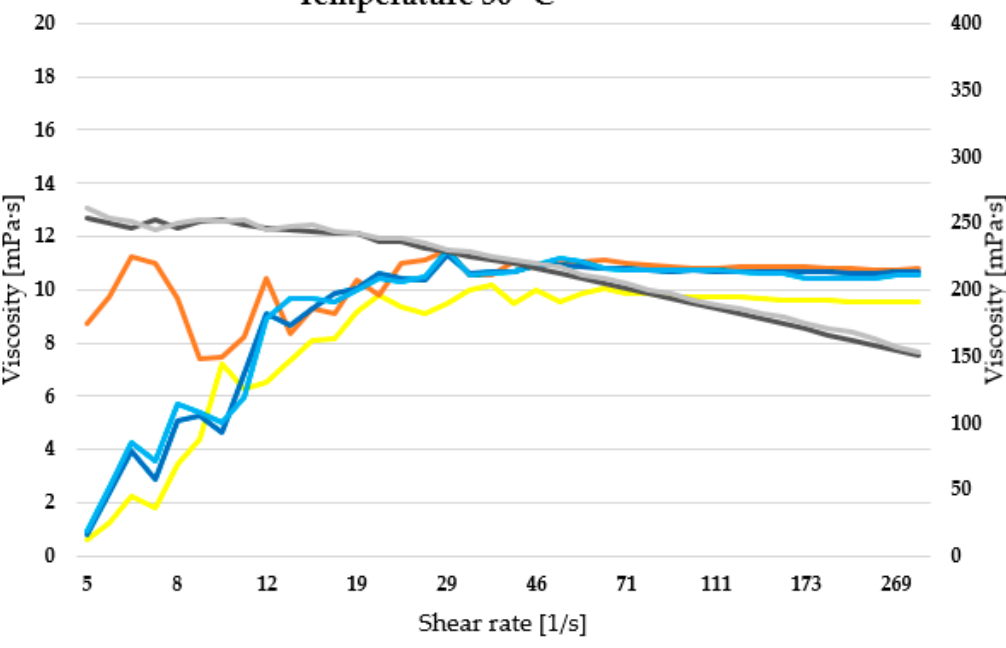

\begin{tabular}{c|c|c|c|c|c|c|c|c|c|c|} 
& 5 & 8 & 12 & 19 & 29 & 46 & 71 & 111 & 173 & 269 \\
\cline { 2 - 9 } & $0.59 \pm 0.04$ & $3.42 \pm 0.05$ & $6.50 \pm 0.09$ & $9.14 \pm 0.02$ & $9.46 \pm 0.07$ & $9.99 \pm 0.09$ & $9.87 \pm 0.03$ & $9.74 \pm 0.07$ & $9.61+0.07$ & $9.56+0.03$ \\
\hline
\end{tabular}

\begin{tabular}{l|l|l|l|l|l|l|l|l|l|l|l}
\multirow{2}{*}{ PVA+TBE } & $8.73 \pm 0.09$ & $9.67 \pm 0.04$ & $10.42 \pm 0.11$ & $10.39 \pm 0.13$ & $11.49 \pm 0.15$ & $10.95 \pm 0.12$ & $11.01 \pm 0.13$ & $10.83 \pm 0.16$ & $10.84 \pm 0.13$ & $10.77 \pm 0.17$ \\
\cline { 2 - 9 }
\end{tabular}

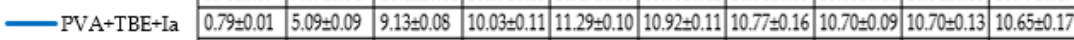

\begin{tabular}{l|l|l|l|l|l|l|l|l|l|l|l|}
\multirow{2}{*}{$\mathrm{PVA}+\mathrm{Ia}$} & $0.89 \pm 0.05$ & $5.69 \pm 0.06$ & $8.94 \pm 0.03$ & $9.99 \pm 0.07$ & $11.50 \pm 0.09$ & $10.90 \pm 0.11$ & $10.76 \pm 0.13$ & $10.71 \pm 0.11$ & $10.42 \pm 0.09$ & $10.55 \pm 0.15$ \\
\cline { 2 - 9 } \\
\cline { 2 - 8 }
\end{tabular}

\begin{tabular}{lll|l|l|l|l|l|l|l|l|l|l|l}
$n$ & $\mathrm{PVA}+\mathrm{TBE}+\mathrm{Ch}$ & $253.83 \pm 1.9$ & $246.21+2.3$ & $246.08 \pm 1.9$ & $242.47 \pm 1.1$ & $228.79 \pm 1.6$ & $215.74 \pm 1.7$ & $200.92 \pm 0.9$ & $185.42 \pm 1.9$ & $170.13 \pm 1.9$ & $154.45 \pm 1.7$
\end{tabular}

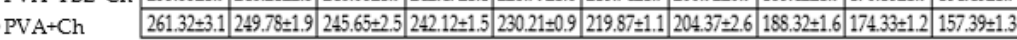

(B)

Figure 3. Cont. 


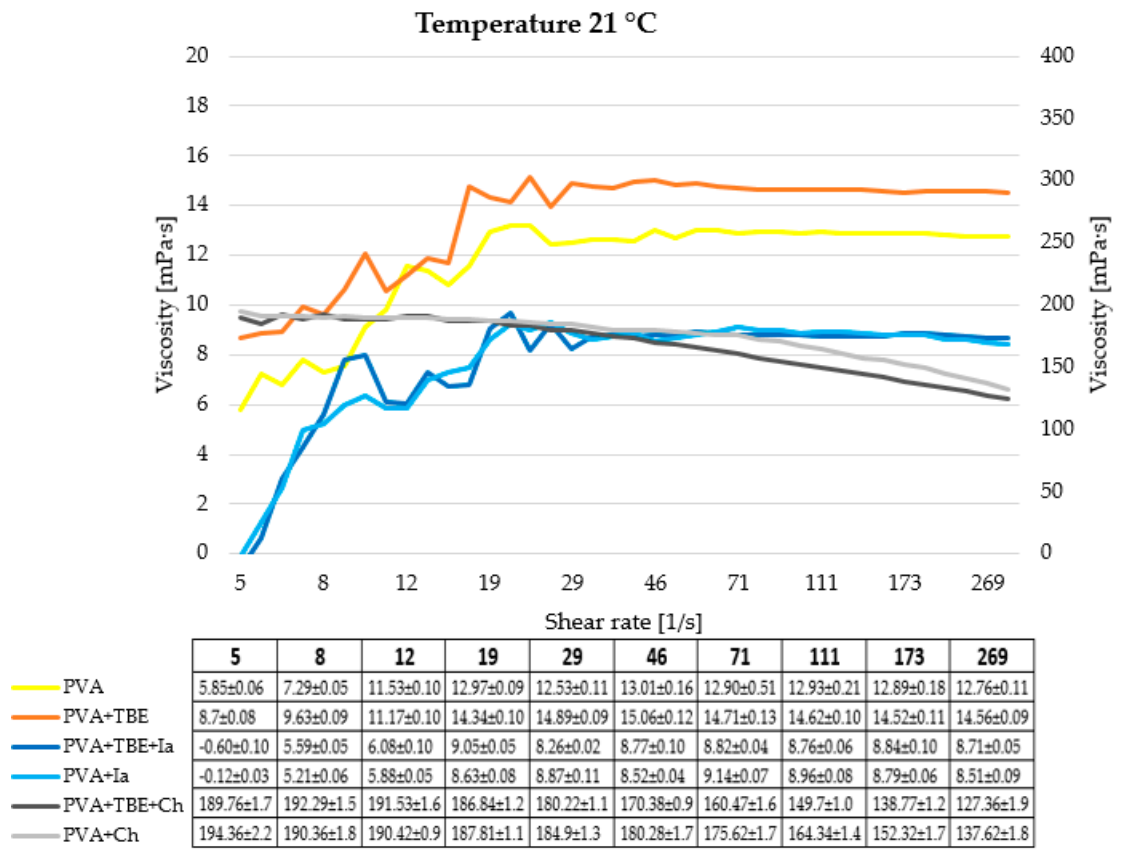

(C)

Figure 3. Relationship between viscosity and shear rate at $37^{\circ} \mathrm{C}(\mathrm{A}), 30^{\circ} \mathrm{C}(\mathbf{B}), 21^{\circ} \mathrm{C}(\mathbf{C})$ for PVA, PVA + TBE, PVA + TBE + itaconic acid (Ia), and PVA + TBE + Ch.

\subsection{Total Phenolic Content (TPC)}

Phenolic compounds are plant-derived metabolites. According to the literature, they have significant $-\mathrm{OH}$ structures for scavenging free radicals and, therefore, an important antioxidant capacity [21]. The PVA, PVA + Ia, and PVA + Ch films (without any added TBE) contained no phenolic compounds; therefore, data are not shown on the chart for these particular films. The total phenolic content of films containing TBE was in the range of $0.167-0.208 \mathrm{mg}$ gallic acid/100 $\mathrm{mL}$ film-forming solution, the results of which are illustrated in Figure 4. The testing temperature was constant (room temperature). The content of phenolics determined in the film-forming solutions differed significantly according to the type of biopolymer used. The PVA $+\mathrm{Ch}$ films containing TBE registered the highest TPC, namely, $0.208 \mathrm{mg}$ gallic acid/100 $\mathrm{mL}$ film-forming solution, being significantly different from the other two types of films.

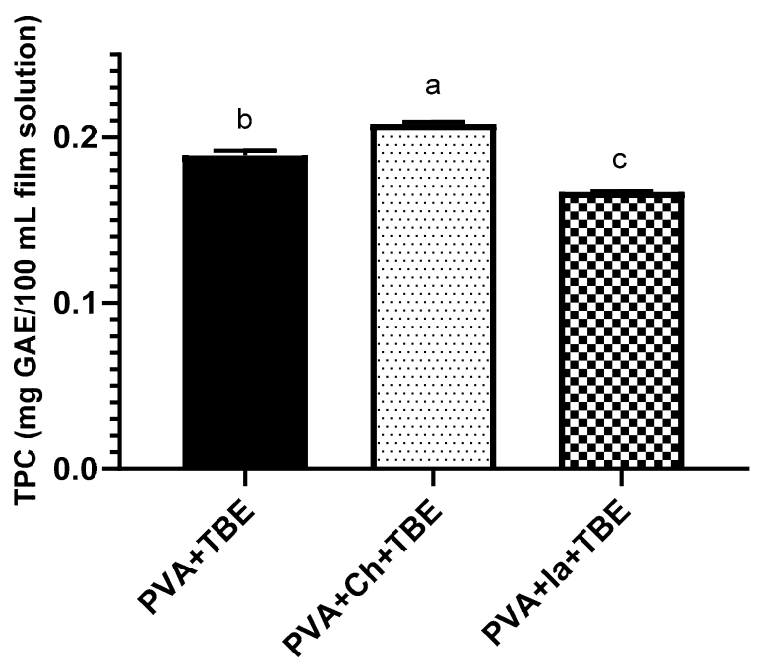

Figure 4. Total phenolic content (Folin-Ciocalteu method). 
The total phenolic content of film-forming solutions may deliver important antioxidant activity, but was not tested in the present paper considering the focus of choosing the best candidate with the highest antimicrobial property for active packaging. Arcan and Yemenicioglu (2011) reported a significant antioxidant activity of zein films enriched with phenolic compounds such as catechin, gallic acid, p-hydroxybenzoic acid, and ferulic acid, justified by the existance of soluble phenolics in the film [63].

The total phenolic content of the film-forming solutions is expressed as gallic acid equivalents (GAE) in $\mathrm{mg} / 100 \mathrm{~mL}$ sample. Values are expressed as mean values $\pm \mathrm{SD}, n=3$, and are followed by different letters $(\mathrm{a}-\mathrm{c})$, indicating significant differences $(p<0.05)$ between the type of films (one-way ANOVA - Multiple comparison test - Tukey multiple range test $(p=0.05)$; GraphPad Prism Version 8.0.1, Graph Pad Software, Inc., San Diego, CA, USA).

\subsection{Antimicrobial Activity}

The antimicrobial properties of active packaging can be achieved by direct incorporation of natural antimicrobial compounds, with a high interest being the agro-industrial waste-derived bioactive compounds. The antimicrobial activity of the PVA, PVA + Ia, and PVA + Ch films, all containing TBE, and against the selected microorganisms, is presented in Table 4 below.

Table 4. Minimum inhibitory concentration (mg dry weight $/ \mathrm{mL}$ ) against S. aureus, E. coli, P. aeruginosa, S. enterica Enteritidis, and S. enterica Typhimurium.

\begin{tabular}{cccccc}
\hline & $\begin{array}{c}\text { G (+) } \\
\text { Bacteria }\end{array}$ & & \multicolumn{2}{c}{ G (-) Bacteria } & \\
\hline Samples & S. aureus & E. coli & P. aeruginosa & $\begin{array}{c}\text { S. enterica } \\
\text { Enteritidis }\end{array}$ & $\begin{array}{c}\text { S. enterica } \\
\text { Typhimurium }\end{array}$ \\
\hline PVA & n.b. & n.b. & n.b. & n.b. & n.b. \\
PVA + TBE & n.b. & n.b. & n.b. & n.b. & n.b. \\
PVA + Ch + TBE & $<0.078$ & 5.00 & $<0.078$ & 0.312 & 5.00 \\
PVA + Ch & 0.156. & 10 & 0.156 & 0.624 & 10 \\
PVA + Ia + TBE & n.b. & n.b. & 2.5 & n.b. & n.b. \\
PVA + Ia & n.b. & n.b. & 5.00 & n.b. & n.b. \\
\hline
\end{tabular}

In accordance with the guideline described by O'Donnell et al. (2010) [57], the PVA + Ch films containing TBE showed good antibacterial activity toward S. aureus and P. aeruginosa, with a MIC of $<0.078 \mathrm{mg} \mathrm{DW} / \mathrm{mL}$, while toward S. enterica Enteritidis, they showed a moderate antimicrobial capacity, with a MIC of $0.312 \mathrm{mg} \mathrm{DW} / \mathrm{mL}$, and no bioactivity against the other tested strains were exhibited. The TBE considering its carotenoids and phenolics content, previously reported with good antimicrobial capacity [18], may significantly contribute to this antibacterial capacity. The PVA + Ch film registered a moderate antibacterial effect toward S. aureus and P. aeruginosa strains, with a MIC of $0.156 \mathrm{mg} \mathrm{DW} / \mathrm{mL}$, and a mild inhibition capacity toward S. enterica Enteritidis. The precise mechanism of $\mathrm{Ch}$ antibacterial capacity is not fully elucidated. The main explanation relies on the interaction between its positively charged amino group and the negatively charged microbial cell membranes, the interaction of which contributes to the leakage of proteinaceous and other intracellular constituents of the bacteria [64]. The PVA had no antimicrobial capacity, in line with a previously reported PVA-based film study [65]. The PVA + Ia film containing TBE registered a MIC of $2.5 \mathrm{mg}$ DW/mL, and the PVA + Ia without TBE registered a MIC of $5 \mathrm{mg}$ DW/mL against $P$. aeruginosa; therefore, both had no antibacterial effect. This fact could be explained by the low concentration of Ia used, precisely $1 \%$, insufficient to exert its previously reported antimicrobial characteristics $[66,67]$. Both the inherent antibacterial characteristics and film forming capacity of $\mathrm{Ch}$ make it the best candidate for use as an active packaging material $[68,69]$. 
This enhanced antibacterial activity of TBE-containing films could be explained by the important antibacterial capacity of TBE previously reported in our study [58]. Other researchers have also found an enhanced antibacterial capacity of Ch-based films by incorporation of natural extracts, whereas the present study supports the idea of using the agro-industrial by-products extracts, precisely, the industrially derived tomato seeds and peels, for increasing their value and range of applications. Mathew and Abraham (2008) [70] showed that the shelf-life of food has been extended by ferulic acid-incorporated starch-chitosan blend films. In addition, the incorporation of garlic oil and nisin enhanced the antimicrobial activity of chitosan film [71].

\subsection{Physical Characterization of Solid Films}

The physical appearance of the films is illustrated in Figure 5. Six types of films were obtained and presented as PVA (control), PVA + Ia, PVA + Ch, PVA + TBE, PVA + Ia + TBE, and PVA + Ch + TBE. In addition, $15 \mathrm{~mL}$ of the PVA-based film solutions entirely covered the surface of the Petri dishes, and when solidified, the films easily peeled off the plates. Each film type was visually homogeneous with no bubbles inside. From all the obtained films, the PVA film was perfectly transparent compared to the other sample films, and it was the most fragile one. The addition of Ia, $\mathrm{Ch}$, and TBE contributed substantially to the resistance of the PVA films, and at the same time, to the opacity and color of the films. Itaconic acid and chitosan reduced the transparency of the PVA films and conferred their rigidity by making them brittle. The addition of TBE reduced the films' rigidity induced by Ia and Ch by imprinting them with a slight elasticity. Considering the color of the films, TBE with a concentration of $9 \%$ imprinted yellow colors of different tones to all tested films. Similar studies point out that vegetal extracts such as mint extract or pomegranate peel extract might imprint color to the PVA-based films even at a low concentration of $0.1 \%$ [65]. The unevenness of the PVA films color might be associated with the different distribution of pigments existing in TBE (lutein, $\beta$-carotene) due to their different molecular mass, because of their Brownian motion, and because of colloidal interactions, until the films are completely solidified [72].
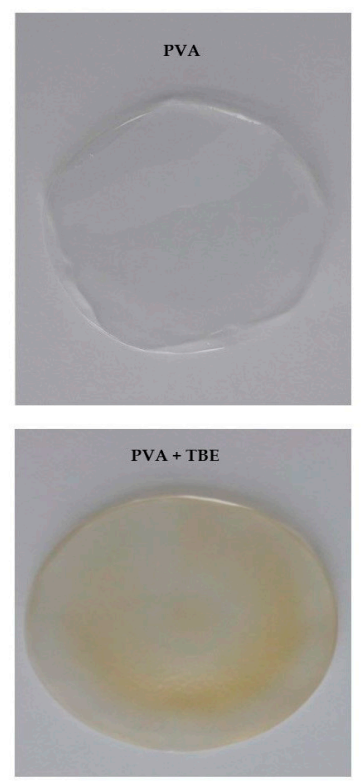
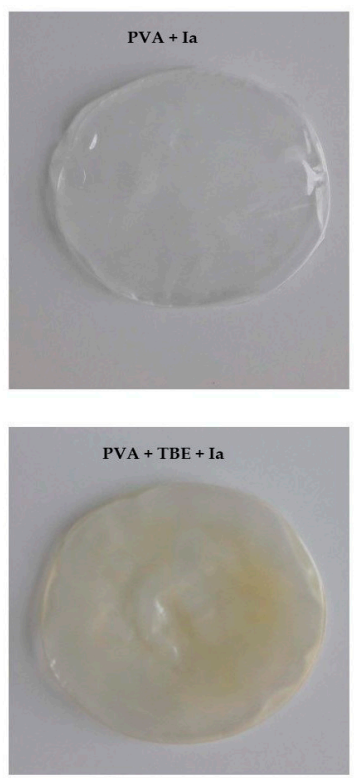
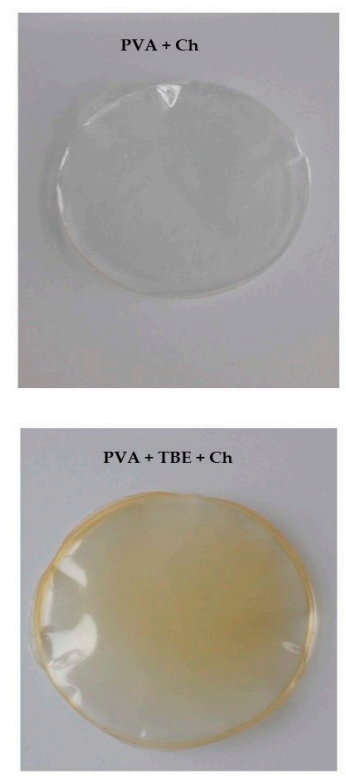

Figure 5. The physical appearance of the obtained films.

Considering the physical measurements (Table 5), all the obtained films had a diameter of less than $8.5 \mathrm{~cm}$, a weight above $0.4 \mathrm{~g}$, a thickness over $0.3 \mathrm{~mm}$, and a density higher than $2.4 \mathrm{~g} / \mathrm{cm}^{3}$. The largest diameter was registered for PVA film $(8.33 \mathrm{~mm} \pm 0.15 \mathrm{~mm})$, while the addition of bioactive compounds (Ia, Ch, and TBE) narrowed down the films' diameter, making them dense and compact. 
As we expected, the addition of bioactive constituents increased the weight, thickness, and density, with the PVA $+\mathrm{Ch}+\mathrm{TBE}$ films recording the highest values for these parameters.

Table 5. The physical measurements of the solid PVA-based films; the shown data represent the mean value of three replicates with the standard deviation $( \pm)$.

\begin{tabular}{ccccc}
\hline Sample & Diameter $(\mathbf{c m})$ & Weight $(\mathrm{g})$ & Thickness $(\mathbf{m m})$ & Density $\left(\mathrm{g} / \mathrm{cm}^{\mathbf{3}}\right)$ \\
\hline PVA & $8.33 \pm 0.15$ & $0.44 \pm 0.00$ & $0.03 \pm 0.01$ & $2.40 \pm 0.79$ \\
PVA + TBE & $7.95 \pm 0.07$ & $0.46 \pm 0.00$ & $0.04 \pm 0.01$ & $3.70 \pm 1.35$ \\
PVA + Ia & $8.27 \pm 0.06$ & $0.61 \pm 0.04$ & $0.04 \pm 0.01$ & $4.58 \pm 1.33$ \\
PVA + Ia + TBE & $7.87 \pm 0.06$ & $0.61 \pm 0.02$ & $0.04 \pm 0.01$ & $4.63 \pm 1.44$ \\
PVA + Ch & $8.00 \pm 0.00$ & $0.57 \pm 0.01$ & $0.06 \pm 0.01$ & $6.79 \pm 1.08$ \\
PVA + Ch + TBE & $8.07 \pm 0.12$ & $0.64 \pm 0.03$ & $0.06 \pm 0.01$ & $7.55 \pm 1.40$ \\
\hline
\end{tabular}

FTIR is a useful method to identify specific molecular structures or the vibration of functional groups from certain matrices [73,74]. For the present study, FTIR analysis was performed for PVA-based films supplemented with TBE (Figure 6) in order to observe the influence of tomato waste-based extract on the PVA formulations. For all investigated samples, a large band with a moderate height around $3300 \mathrm{~cm}^{-1}$ was observed, vibrations that were attributed to the presence of inter- and intramolecular hydrogen-bonded -OH groups from the PVA matrix [75]. Peaks of different heights situated between 2800 and $3000 \mathrm{~cm}^{-1}$ were observed for all tested films (2906 and $2939 \mathrm{~cm}^{-1}$ for PVA, 2908 and $2939 \mathrm{~cm}^{-1}$ for PVA + TBE, 2910 and 3022 for PVA + Ia, 2854 and 2922 for PVA + Ia + TBE, and 2854 and $2924 \mathrm{~cm}^{-1}$ for PVA+Ch and PVA $+\mathrm{Ch}+\mathrm{TBE})$. Their presence was connected with vibrations of $\mathrm{C}-\mathrm{H}$ bonding specific to polyalcohols, as the scientific literature suggests [74-76]. Moderate peaks associated with $-C-C-C$ - vibrations were identified around $1400 \mathrm{~cm}^{-1}$ (at $1417 \mathrm{~cm}^{-1}$ for PVA, PVA + TBE, and PVA + Ia $+\mathrm{TBE}$; and at $1411 \mathrm{~cm}^{-1}$ for PVA $\left.+\mathrm{Ch}+\mathrm{TBE}\right)$ [75]. The large peak situated around $1000 \mathrm{~cm}^{-1}$ identified in all samples $\left(1087 \mathrm{~cm}^{-1}\right.$ for PVA and PVA + Ia; $1085 \mathrm{~cm}^{-1}$ for PVA + TBE and PVA + Ia + TBE; 1083 $\mathrm{cm}^{-1}$ for PVA $+\mathrm{Ch}$ and PVA $\left.+\mathrm{Ch}+\mathrm{TBE}\right)$ emphasized the presence of $\mathrm{C}-\mathrm{O}-\mathrm{C}$ bonds from PVA [75].

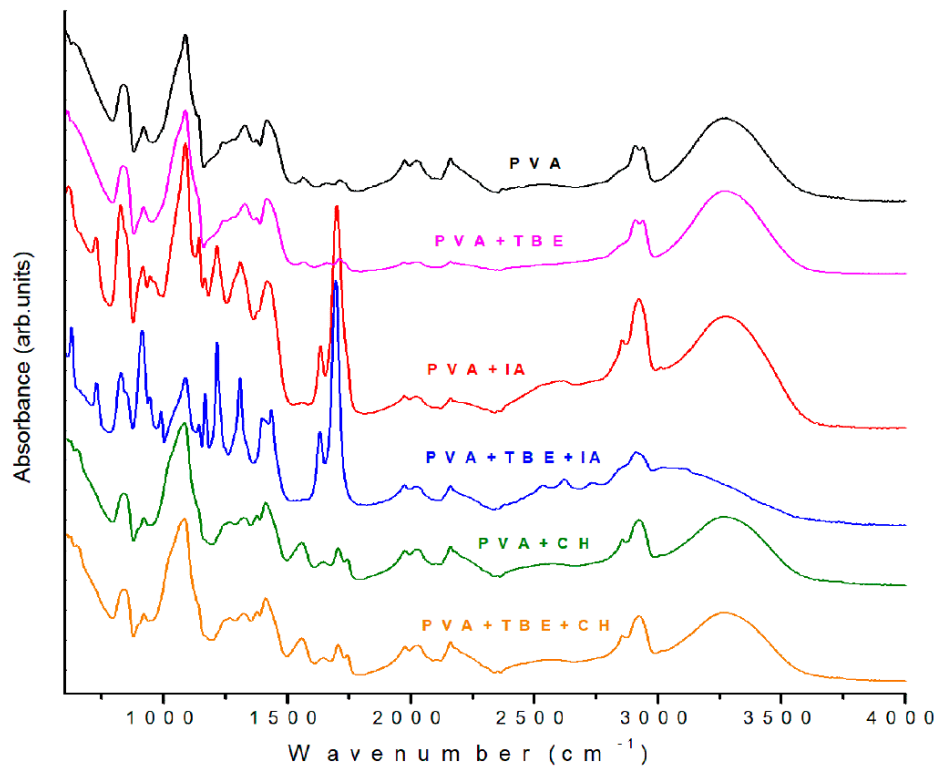

Figure 6. FTIR spectra of the solid films.

The spectra obtained for PVA + Ia + TBE and PVA + Ch + TBE films showed few differences toward the simpler matrices like PVA and PVA + TBE. The film containing itaconic acid showed sharp peaks at 1633 and $1699 \mathrm{~cm}^{-1}$, peaks that can be linked to the presence of $C=O$ bonds, specific to carboxylic groups $[74,77]$. The spectra obtained for the film containing chitosan showed absorbance at 
a wavelength of $1411 \mathrm{~cm}^{-1}$, which is specific to $\mathrm{C}=\mathrm{N}$ bonds [78]. In the case of PVA spectra, it showed a peak at $2160 \mathrm{~cm}^{-1}$, which indicates the presence of $\mathrm{C}=\mathrm{O}$ bonds [75], this particular peak being missing from the rest of the formulations that contained TBE. The incorporation of tomato waste-based extract into the PVA film solutions seemed to attenuate the presence of these aliphatic carbonyl groups.

\section{Conclusions}

Due to consumers' preference for minimally processed and natural products, active packaging is gaining importance; however, bio-packaging films generally exhibit weak mechanical attributes and high water solubility and permeability compared to commercially available polymers. In the present study, films containing poly(vinyl alcohol) $(3 \% \mathrm{wt} . / \mathrm{v})$ and chitosan $(1 \% \mathrm{wt} . / \mathrm{v})$ were enriched with TBE and showed good antibacterial activity toward S. aureus and P. aeruginosa, with a MIC of $<0.078 \mathrm{mg}$ $\mathrm{DW} / \mathrm{mL}$, also having important antimicrobial effects toward all the tested strains. The addition of Ia, $\mathrm{Ch}$, and TBE significantly contributed to the resistance of the PVA films and modified the opacity and color of the films at the same time. Itaconic acid and chitosan reduced the transparency of the PVA films and conferred rigidity by making them brittle, and the addition of TBE imprinted a slight elasticity to the films. The rheological characteristics of the studied films presented shear thinning (chitosan) and shear thickening (itaconic acid and simple films) behaviors. In the first case, the viscosity decreased with the increase in shear rate, and in the second case, it increased and then remained constant with the increase in shear rate. In addition, the total phenolic content of TBE-enriched PVA + Ch film-forming solutions may deliver important antioxidant activity. Therefore, the produced films are suitable for the packaging of a large variety of foods. Considering the high importance of low permeability in developing ideal food packaging materials, our future research will focus on investigating the water permeability of active packaging films enriched with by-products extracts. In subsequent studies, we intend to also examine the anti-adhesive and anti-biofilm activity, in addition to biodegradability assessment, of the newly developed films.

Author Contributions: K.S. was the main author of this work. K.S., L.M., E.S., R.-A.V. and B.-E.T. worked on the experimental part of this research. K.S., L.M., B.-E.T., L.-F.C. and G.-A.M. worked on the documentation and writing part of the article. D.C.V. was the lead supervisor of the group on this project. All authors have read and agreed to the published version of the manuscript.

Funding: This work was supported by a grant of the Romanian National Authority for Scientific Research and Innovation, CCDI-UEFISCDI, project number 27/2018 CO FUND-MANUNET III-NON-ACT-2, within PNCDI III.

Conflicts of Interest: The authors declare no conflict of interest. The funders had no role in the design of the study; in the collection, analyses, or interpretation of data; in the writing of the manuscript, or in the decision to publish the results.

\section{References}

1. Garavand, F.; Rouhi, M.; Razavi, S.H.; Cacciotti, I.; Mohammadi, R. Improving the integrity of natural biopolymer films used in food packaging by crosslinking approach: A review. Int. J. Biol. Macromol. 2017, 104, 687-707. [CrossRef] [PubMed]

2. Nielsen, T.D.; Hasselbalch, J.; Holmberg, K.; Stripple, J. Politics and the plastic crisis: A review throughout the plastic life cycle. Wires Energy Environ. 2019, 9, e360. [CrossRef]

3. Raddadi, N.; Fava, F. Biodegradation of oil-based plastics in the environment: Existing knowledge and needs of research and innovation. Sci. Total Environ. 2019, 679, 148-158. [CrossRef] [PubMed]

4. Blettler, M.C.M.; Wantzen, K.M. Threats Underestimated in Freshwater Plastic Pollution: Mini-Review. Water Air Soil Pollut. 2019, 230, 174. [CrossRef]

5. Wang, M.H.; He, Y.; Sen, B. Research and management of plastic pollution in coastal environments of China. Environ. Pollut. 2019, 248, 898-905. [CrossRef] [PubMed]

6. Available online: http://www3.weforum.org/docs/WEF_The_New_Plastics_Economy.pdf (accessed on 4 February 2020).

7. Jagiello, Z.; Dylewski, L.; Tobolka, M.; Aguirre, J.I. Life in a polluted world: A global review of anthropogenic materials in bird nests. Environ. Pollut. 2019, 251,717-722. [CrossRef] 
8. Cherubini, F.; Ulgiati, S. Crop residues as raw materials for biorefinery systems-A LCA case study. Appl. Energy 2010, 87, 47-57. [CrossRef]

9. Available online: https://www.earthday.org/fact-sheet-single-use-plastics/ (accessed on 4 February 2020).

10. Weiss, M.; Haufe, J.; Carus, M.; Brandão, M.; Bringezu, S.; Hermann, B.; Patel, M.K. A Review of the Environmental Impacts of Biobased Materials. J. Ind. Ecol. 2012, 16, S169-S181. [CrossRef]

11. Hatti-Kaul, R.; Nilsson, L.J.; Zhang, B.; Rehnberg, N.; Lundmark, S. Designing Biobased Recyclable Polymers for Plastics. Trends Biotechnol. 2020, 38, 50-67. [CrossRef]

12. Zhu, Y.; Romain, C.; Williams, C.K. Sustainable polymers from renewable resources. Nature 2016, 540, 354-362. [CrossRef]

13. Iwata, T. Biodegradable and bio-based polymers: Future prospects of eco-friendly plastics. Angew. Chem. Int. Ed. Engl. 2015, 54, 3210-3215. [CrossRef] [PubMed]

14. Mitrea, L.; Vodnar, D.C. Klebsiella pneumoniae-A Useful Pathogenic Strain for Biotechnological Purposes: Diols Biosynthesis under Controlled and Uncontrolled pH Levels. Pathogens 2019, 8, 293. [CrossRef] [PubMed]

15. Available online: http://www.fao.org/fileadmin/templates/agns/pdf/jecfa/cta/61/PVA.pdf (accessed on 4 February 2020).

16. Wong, C.Y.; Wong, W.Y.; Loh, K.S.; Daud, W.R.W.; Lim, K.L.; Khalid, M.; Walvekar, R. Development of Poly(Vinyl Alcohol)-Based Polymers as Proton Exchange Membranes and Challenges in Fuel Cell Application: A Review. Polym. Rev. 2019, 171-202. [CrossRef]

17. Kanatt, S.R.; Makwana, S.H. Development of active, water-resistant carboxymethyl cellulose-poly vinyl alcohol-Aloe vera packaging film. Carbohydr. Polym. 2020, 227, 115303. [CrossRef]

18. Szabo, K.; Diaconeasa, Z.; Catoi, A.F.; Vodnar, D.C. Screening of Ten Tomato Varieties Processing Waste for Bioactive Components and Their Related Antioxidant and Antimicrobial Activities. Antioxidants 2019, 8, 292. [CrossRef]

19. Călinoiu, L.F.; Mitrea, L.; Precup, G.; Bindea, M.; Rusu, B.; Szabo, K.; Dulf, F.V.; Ştefănescu, B.E.; Vodnar, D.C. Sustainable use of agro-industrial wastes for feeding 10 billion people by 2050. In Professionals in Food Chains: Ethics, Roles and Responsibilities; Wageningen Academic Publishers: Wageningen, The Netherlands, 2018.

20. Bilal, M.; Iqbal, H.M.N. Naturally-derived biopolymers: Potential platforms for enzyme immobilization. Int. J. Biol. Macromol. 2019, 130, 462-482. [CrossRef]

21. Calinoiu, L.F.; Catoi, A.F.; Vodnar, D.C. Solid-State Yeast Fermented Wheat and Oat Bran as A Route for Delivery of Antioxidants. Antioxidants 2019, 8, 372. [CrossRef]

22. Mitrea, L.; Calinoiu, L.F.; Precup, G.; Bindea, M.; Rusu, B.; Trif, M.; Stefanescu, B.E.; Pop, I.D.; Vodnar, D.C. Isolated Microorganisms for Bioconversion of Biodiesel-Derived Glycerol Into 1,3-Propanediol. Bull. Univ. Agric. Sci. Vet. Med. Cluj-Napoca-Food Sci. Technol. 2017, 74, 43-49. [CrossRef]

23. Saini, R.K.; Moon, S.H.; Keum, Y.S. An updated review on use of tomato pomace and crustacean processing waste to recover commercially vital carotenoids. Food Res. Int. 2018, 108, 516-529. [CrossRef]

24. Trif, M.; Vodnar, D.C.; Mitrea, L.; Rusu, A.V.; Socol, C.T. Design and Development of Oleoresins Rich in Carotenoids Coated Microbeads. Coatings 2019, 9, 235. [CrossRef]

25. Szabo, K.; Catoi, A.F.; Vodnar, D.C. Bioactive Compounds Extracted from Tomato Processing by-Products as a Source of Valuable Nutrients. Plant Foods Hum. Nutr. 2018, 73, 268-277. [CrossRef]

26. Calinoiu, L.F.; Vodnar, D.C. Whole Grains and Phenolic Acids: A Review on Bioactivity, Functionality, Health Benefits and Bioavailability. Nutrients 2018, 10, 1615. [CrossRef]

27. Strati, I.F.; Oreopoulou, V. Recovery of carotenoids from tomato processing by-products-A review. Food Res. Int. 2014, 65, 311-321. [CrossRef]

28. Calinoiu, L.F.; Vodnar, D.C. Thermal Processing for the Release of Phenolic Compounds from Wheat and Oat Bran. Biomolecules 2019, 10, 21. [CrossRef]

29. Kuenz, A.; Krull, S. Biotechnological production of itaconic acid-things you have to know. Appl. Microbiol. Biotechnol. 2018, 102, 3901-3914. [CrossRef]

30. Weastra SRO. Available online: https://www.igb.fraunhofer.de/content/dam/igb/en/documents/publications/ BioConSepT_Market-potential-for-selected-platform-chemicals_ppt1.pdf (accessed on 4 February 2020).

31. Regestein, L.; Klement, T.; Grande, P.; Kreyenschulte, D.; Heyman, B.; Massmann, T.; Eggert, A.; Sengpiel, R.; Wang, Y.; Wierckx, N.; et al. From beech wood to itaconic acid: Case study on biorefinery process integration. Biotechnol. Biofuels 2018, 11, 279. [CrossRef] 
32. Teleky, B.E.; Vodnar, D.C. Biomass-Derived Production of Itaconic Acid as a Building Block in Specialty Polymers. Polymers 2019, 11, 1035. [CrossRef]

33. Fuciños, C.F.P.; Amado, I.R.; Míguez, M.; Fajardo, P.; Pastrana, L.M.; Rúa, M.L. Smart Nanohydrogels for Controlled Release of Food Preservatives; Elseviser: Amsterdam, The Netherlands, 2016.

34. González-Henríquez, C.M.; Sarabia-Vallejos, M.A.; Rodriguez-Hernandez, J. Polymers for additive manufacturing and 4D-printing: Materials, methodologies, and biomedical applications. Prog. Polym. Sci. 2019, 94, 57-116. [CrossRef]

35. Top 5 Vendors in the Global Biopolymers Market From 2017-2021: Technavio. Available online: https://www.businesswire.com/news/home/20170112005066/en/Top-5-Vendors-Global-BiopolymersMarket-2017-2021 (accessed on 2 September 2019).

36. Calinoiu, L.F.; Vodnar, D.; Precup, G. A Review: The Probiotic Bacteria Viability under Different Conditions. Bulletin of University of Agricultural Sciences and Veterinary Medicine Cluj-Napoca. Food Sci. Technol. 2016, 73. [CrossRef]

37. Martau, G.A.; Mihai, M.; Vodnar, D.C. The Use of Chitosan, Alginate, and Pectin in the Biomedical and Food Sector-Biocompatibility, Bioadhesiveness, and Biodegradability. Polymers 2019, 11, 1837. [CrossRef]

38. Sinha, V.R.; Singla, A.K.; Wadhawan, S.; Kaushik, R.; Kumria, R.; Bansal, K.; Dhawan, S. Chitosan microspheres as a potential carrier for drugs. Int. J. Pharm. 2004, 274, 1-33. [CrossRef]

39. Cavallaro, G.; Lazzara, G.; Milioto, S. Sustainable nanocomposites based on halloysite nanotubes and pectin/polyethylene glycol blend. Polym. Degrad. Stab. 2013, 98, 2529-2536. [CrossRef]

40. Sanuja, S.; Agalya, A.; Umapathy, M.J. Studies on Magnesium Oxide Reinforced Chitosan Bionanocomposite Incorporated with Clove Oil for Active Food Packaging Application. Int. J. Polym. Mater. Polym. Biomater. 2014, 63, 733-740. [CrossRef]

41. Guerreiro, A.C.; Gago, C.M.L.; Miguel, M.G.C.; Faleiro, M.L.; Antunes, M.D.C. The influence of edible coatings enriched with citral and eugenol on the raspberry storage ability, nutritional and sensory quality. Food Packag. Shelf Life 2016, 9, 20-28. [CrossRef]

42. Kanetis, L.; Exarchou, V.; Charalambous, Z.; Goulas, V. Edible coating composed of chitosan and Salvia fruticosa Mill. extract for the control of grey mould of table grapes. JSCI Food Agric. 2017, 97, 452-460. [CrossRef]

43. Călinoiu, L.-F.; Ştefănescu, B.; Pop, I.; Muntean, L.; Vodnar, D. Chitosan Coating Applications in Probiotic Microencapsulation. Coatings 2019, 9, 194. [CrossRef]

44. Krisanti, E.A.; Naziha, G.M.; Amany, N.S.; Mulia, K.; Handayani, N.A. Effect of biopolymers composition on release profile of iron(II) fumarate from chitosan-alginate microparticles. In IOP Conference Series: Materials Science and Engineering; IOP Publishing: Bristol, UK, 2019.

45. Estevinho, B.N.; Rocha, F.; Santos, L.; Alves, A. Microencapsulation with chitosan by spray drying for industry applications-A review. Trends Food Sci. Technol. 2013, 31, 138-155. [CrossRef]

46. Gonçalves, A.; Estevinho, B.N.; Rocha, F. Microencapsulation of vitamin A: A review. Trends Food Sci. Technol. 2016, 51, 76-87. [CrossRef]

47. Lee, J.B.; Ahn, J.; Lee, J.; Kwak, H.S. The microencapsulated ascorbic acid release in vitro and its effect on iron bioavailability. Arch. Pharm. Res. 2003, 26, 874-879. [CrossRef]

48. Zhang, Z.; Zhang, R.; Chen, L.; McClements, D.J. Encapsulation of lactase (beta-galactosidase) into kappa-carrageenan-based hydrogel beads: Impact of environmental conditions on enzyme activity. Food Chem. 2016, 200, 69-75. [CrossRef]

49. Gupta, C.; Chawla, P.; Arora, S.; Tomar, S.K.; Singh, A.K. Iron microencapsulation with blend of gum arabic, maltodextrin and modified starch using modified solvent evaporation method-Milk fortification. Food Hydrocoll. 2015, 43, 622-628. [CrossRef]

50. Valenzuela, C.; Hernández, V.; Morales, M.S.; Neira-Carrillo, A.; Pizarro, F. Preparation and characterization of heme iron-alginate beads. LWT Food Sci. Technol. 2014, 59, 1283-1289. [CrossRef]

51. Nasui, L.; Vodnar, D.; Socaciu, C. Bioactive Labels for Fresh Fruits and Vegetables. Bulletin of University of Agricultural Sciences and Veterinary Medicine Cluj-Napoca. Food Sci. Technol. 2013, 70, 74-82. [CrossRef]

52. Dong, H.; Cheng, L.; Tan, J.; Zheng, K.; Jiang, Y. Effects of chitosan coating on quality and shelf life of peeled litchi fruit. J. Food Eng. 2004, 64, 355-358. [CrossRef]

53. Guo, Z.; Xing, R.; Liu, S.; Zhong, Z.; Ji, X.; Wang, L.; Li, P. The influence of molecular weight of quaternized chitosan on antifungal activity. Carbohydr. Polym. 2008, 71, 694-697. [CrossRef] 
54. Athayde, A.J.A.A.; de Oliveira, P.D.L.; Guerra, I.C.D.; da Conceição, M.L.; de Lima, M.A.B.; Arcanjo, N.M.O.; Madruga, M.S.; Berger, L.R.R.; de Souza, E.L. A coating composed of chitosan and Cymbopogon citratus(Dc. Ex Nees) essential oil to control Rhizopus soft rot and quality in tomato fruit stored at room temperature. J. Hortic. Sci. Biotechnol. 2016, 91, 582-591. [CrossRef]

55. Dulf, F.V.; Vodnar, D.C.; Dulf, E.H.; Tosa, M.I. Total phenolic contents, antioxidant activities, and lipid fractions from berry pomaces obtained by solid-state fermentation of two Sambucus species with Aspergillus niger. J. Agric. Food Chem. 2015, 63, 3489-3500. [CrossRef]

56. Vodnar, D.C.; Calinoiu, L.F.; Dulf, F.V.; Stefanescu, B.E.; Crisan, G.; Socaciu, C. Identification of the bioactive compounds and antioxidant, antimutagenic and antimicrobial activities of thermally processed agro-industrial waste. Food Chem. 2017, 231, 131-140. [CrossRef]

57. O'Donnell, F.; Smyth, T.J.; Ramachandran, V.N.; Smyth, W.F. A study of the antimicrobial activity of selected synthetic and naturally occurring quinolines. Int. J. Antimicrob. Agents 2010, 35, 30-38. [CrossRef]

58. Szabo, K.; Dulf, F.V.; Diaconeasa, Z.; Vodnar, D.C. Antimicrobial and antioxidant properties of tomato processing byproducts and their correlation with the biochemical composition. LWT 2019, 116, 108558. [CrossRef]

59. Strati, I.F.; Gogou, E.; Oreopoulou, V. Enzyme and high pressure assisted extraction of carotenoids from tomato waste. Food Bioprod. Process. 2015, 94, 668-674. [CrossRef]

60. Ding, J.; Chen, S.-C.; Wang, X.-L.; Wang, Y.-Z. Preparation and Rheological Behaviors of Thermoplastic Poly(vinyl alcohol) Modified by Lactic Acid. Ind. Eng. Chem. Res. 2011, 50, 9123-9130. [CrossRef]

61. Muresan, V.; Danthine, S.; Racolta, E.; Muste, S.; Blecker, C. The Influence of Particle Size Distribution on Sunflower Tahini Rheology and Structure. J. Food Process Eng. 2014, 37, 411-426. [CrossRef]

62. Merlusca, I.P.; Ibanescu, C.; Tuchilus, C.; Danu, M.; Atanase, L.I.; Popa, I.M. Characterization of Neomycin-Loaded Xanthan-Chitosan Hydrogels for Topical Applications. Cellul. Chem. Technol. 2019, 53, 709-719. [CrossRef]

63. Arcan, I.; Yemenicioğlu, A. Incorporating phenolic compounds opens a new perspective to use zein films as flexible bioactive packaging materials. Food Res. Int. 2011, 44, 550-556. [CrossRef]

64. Shahidi, F.; Arachchi, J.K.V.; Jeon, Y.-J. Food applications of chitin and chitosans. Trends Food Sci. Technol. 1999, 10, 37-51. [CrossRef]

65. Kanatt, S.R.; Rao, M.S.; Chawla, S.P.; Sharma, A. Active chitosan-polyvinyl alcohol films with natural extracts. Food Hydrocoll. 2012, 29, 290-297. [CrossRef]

66. Birajdar, M.S.; Cho, H.; Seo, Y.; Choi, J.; Park, H. Surface conjugation of poly(dimethyl siloxane) with itaconic acid-based materials for antibacterial effects. Appl. Surf. Sci. 2018, 437, 245-256. [CrossRef]

67. Sakthivel, M.; Franklin, D.S.; Sudarsan, S.; Chitra, G.; Sridharan, T.B.; Guhanathan, S. Investigation on $\mathrm{pH} /$ salt-responsive multifunctional itaconic acid based polymeric biocompatible, antimicrobial and biodegradable hydrogels. React. Funct. Polym. 2018, 122, 9-21. [CrossRef]

68. Ouattara, B.; Simard, R.E.; Piette, G.; Begin, A.; Holley, R.A. Diffusion of Acetic and Propionic Acids from Chitosan-based Antimicrobial Packaging Films. J. Food Sci. 2000, 65, 768-773. [CrossRef]

69. Rao, M.S.; Kanatt, S.R.; Chawla, S.P.; Sharma, A. Chitosan and guar gum composite films: Preparation, physical, mechanical and antimicrobial properties. Carbohydr. Polym. 2010, 82, 1243-1247. [CrossRef]

70. Mathew, S.; Abraham, T.E. Characterisation of ferulic acid incorporated starch-chitosan blend films. Food Hydrocoll. 2008, 22, 826-835. [CrossRef]

71. Pranoto, Y.; Rakshit, S.K.; Salokhe, V.M. Enhancing antimicrobial activity of chitosan films by incorporating garlic oil, potassium sorbate and nisin. LWT Food Sci. Technol. 2005, 38, 859-865. [CrossRef]

72. Sand, A.; Kniivilä, J.; Toivakka, M.; Hjelt, T. Structure formation mechanisms in consolidating pigment coatings-Simulation and visualisation. Chem. Eng. Process. Process Intensif. 2011, 50, 574-582. [CrossRef]

73. Luzi, F.; Pannucci, E.; Santi, L.; Kenny, J.M.; Torre, L.; Bernini, R.; Puglia, D. Gallic Acid and Quercetin as Intelligent and Active Ingredients in Poly(vinyl alcohol) Films for Food Packaging. Polymers 2019, 11, 1999. [CrossRef]

74. Mitrea, L.; Ranga, F.; Fetea, F.; Dulf, F.V.; Rusu, A.; Trif, M.; Vodnar, D.C. Biodiesel-Derived Glycerol Obtained from Renewable Biomass-A Suitable Substrate for the Growth of Candida zeylanoides Yeast Strain ATCC 20367. Microorganisms 2019, 7, 265. [CrossRef] 
75. Harun-or-Rashid, M.D.; Saifur Rahaman, M.D.; Enamul Kabir, S.; Khan, M.A. Effect of hydrochloric acid on the properties of biodegradable packaging materials of carboxymethylcellulose/poly(vinyl alcohol) blends. J. Appl. Polym. Sci. 2016, 133. [CrossRef]

76. Li, R.; Wang, Y.; Xu, J.; Ahmed, S.; Liu, Y. Preparation and Characterization of Ultrasound Treated Polyvinyl Alcohol/Chitosan/DMC Antimicrobial Films. Coatings 2019, 9, 582. [CrossRef]

77. MilosavljevicÌ, N.B.; KljajevicÌ, L.M.; Popovicİ, I.G.; FilipovicÌ, J.M.; Kalagasidis KrusİCEicÌ, M.T. Chitosan, itaconic acid and poly(vinyl alcohol) hybrid polymer networks of high degree of swelling and good mechanical strength. Polym. Int. 2009, 59, 686-694. [CrossRef]

78. Liu, Y.; Wang, S.; Lan, W.; Qin, W. Fabrication and Testing of PVA/Chitosan Bilayer Films for Strawberry Packaging. Coatings 2017, 7, 109. [CrossRef]

(C) 2020 by the authors. Licensee MDPI, Basel, Switzerland. This article is an open access article distributed under the terms and conditions of the Creative Commons Attribution (CC BY) license (http://creativecommons.org/licenses/by/4.0/). 